\title{
Erratum to: Müllerian Agenesis: Diagnosis, Treatment, and Future Fertility
}

Jamie Stanhiser and Marjan Attaran

\section{Erratum to:}

Chapter 6 in: S.M. Pfeifer (ed.), Congenital Müllerian Anomalies, DOI 10.1007/978-3-319-27231-3_6

The coauthor of Chapter 6 is Jamie Stanhiser and her name was incorrectly spelled as Stanheiser in the original publication. It has been corrected in the chapter and the volume front matter.

The updated online version of this chapter can be found at https://doi.org/10.1007/978-3-319-27231-3_6 